\title{
HYDATID DISEASE OF THE LUNG
}

\author{
Sqn Ldr S PIPLANI ${ }^{*}$, Wg Cdr P KUMAR ${ }^{+}$
}

MJAFI 1999; 55 : 161-162

Key Words: Albendazole; Echinococcus; Hydatid cyst; Pulmonary hydatidosis.

Introduct tilocularis and vogeli. The dog and certain wild canines are the definitive hosts. Cysts develop in the intermediate hosts-sheep, cattle, humans, goats, camels and horses. Man is the accidental dead end host. He gets infected while handling dogs with contaminated hair, or by consuming contaminated vegetables or water. The disease is common in sheep raising countries where dogs have access to infected offal. In India, clinical reports from various parts of the country suggest high endemicity of the disease [1]. It commonly affects the liver and lungs. Pulmonary involvement has been reported in 3-32\% of patients [2]. Most of the cases are detected incidentally during routine $X$-ray or ultrasound. We report here a case of multiple hydatid cysts of lung.

\section{Case Report}

A 55-years-old male, resident of Assam, driver by occupation, presented to our hospital with chest pain of 7 days duration. The pain was located over the right mammary region and it was dull aching in character. He denied history of cough, haemoptysis, fever or dyspnoea.

Clinical examination revealed an afebrile normotensive male

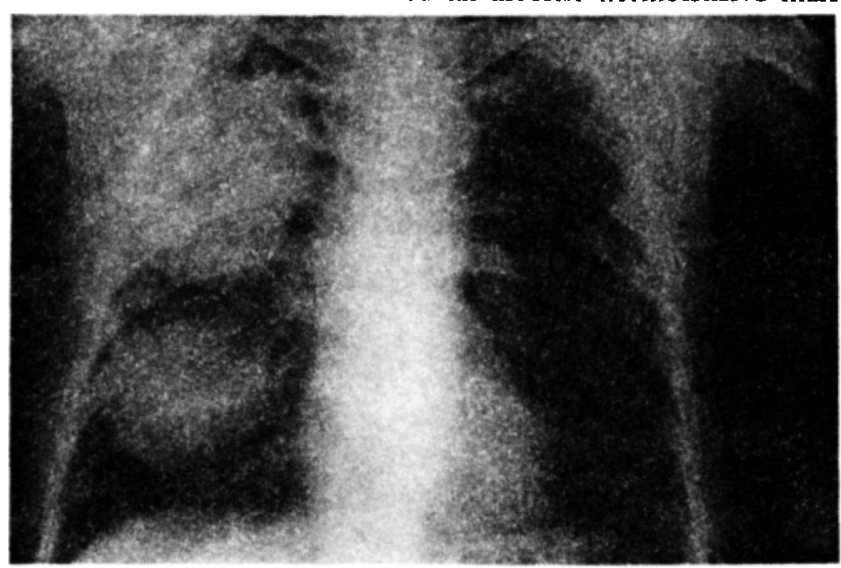

Fig. 1: Two large hydatid cysts in the right lung, in upper and lower lobes, measuring $7 \mathrm{~cm}$ and $6 \mathrm{~cm}$ respectively without pallor, clubbing or lymphadenopathy. Examination of respiratory system, CVS, abdomen and CNS were normal. Haemogram, urinalysis and resting electrocardiogram were also normal. Chest radiograph (Fig 1) revealed two large round homogeneous opacities in right upper and lower lobes, $7 \mathrm{~cm}$ and $6 \mathrm{~cm}$ in diameter respectively. CT scan of chest (Fig 2) showed them to be thin walled unilocular cysts with hypodense contents. The lower lobe lesion showed a nodular calcification in the wall. Ultrasound examination of the abdomen was normal. Immunodiagnostic techniques were not available. A diagnosis of hydatid cysts was made and surgery was advised. Patient however refused surgery and he was therefore given a trial of Albendazole. After initial 2 weeks of treatment he developed cough, pleuritic chest pain and expectorated $100-150 \mathrm{ml}$ of white salty fluid. Clinical examination revealed fever and crepitations in the right mammary region. There was polymorphonuclear lecuocytosis. Radiograph of the chest showed a large cavity in the RLZ, bronchopulmonary fistula and nonhomogeneous opacities suggestive of rupture of the lower cyst with secondary pneumonia. Patient was given appropriate parenteral antibiotics while albendazole was continued. The fever and pneumonia gradually subsided. Three weeks later he once again developed cough, chest pain and fever. Chest radiograph revealed (Fig 3) the 'water-lily' sign as a result of rupture into a bronchus and partial collapse of the cyst membranes. While in hospital he coughed out $50-100 \mathrm{ml}$ of white slimy fluid, microscopic examination of which did not reveal scolices or hooklets. Patient was again exhibited a course of antibiotics and he recovered. He has been advised to continue Albendazole for 12 weeks and is being reviewed monthly in $\mathrm{OPD}$ with serial radiographs.

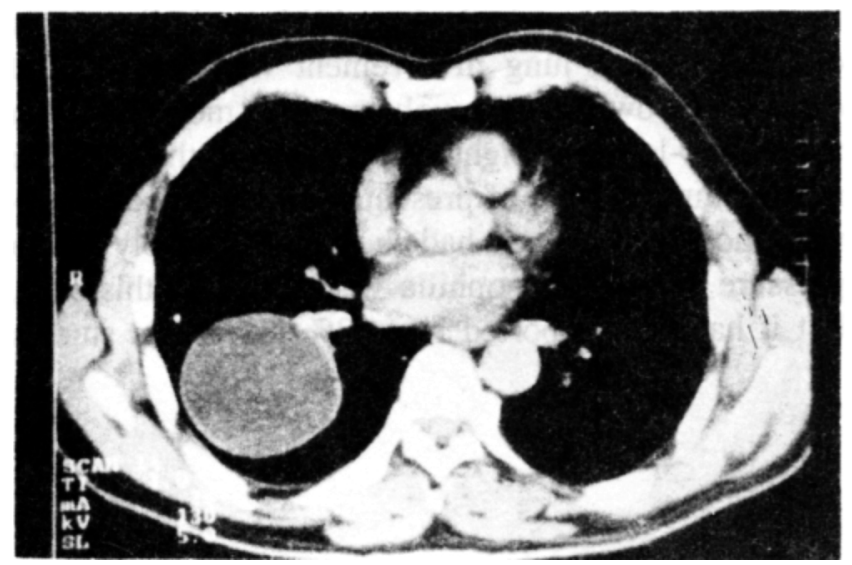

Fig. 2: CECT scan of chest shows the cyst to be thin walled, unilocular with hypodense contents. There is no enhancement following contrast

\footnotetext{
"Graded Specialist (Medicine), ${ }^{+}$Classified Specialist (Medicine), 5 Airforce Hospital, Clo 99 APO.
} 


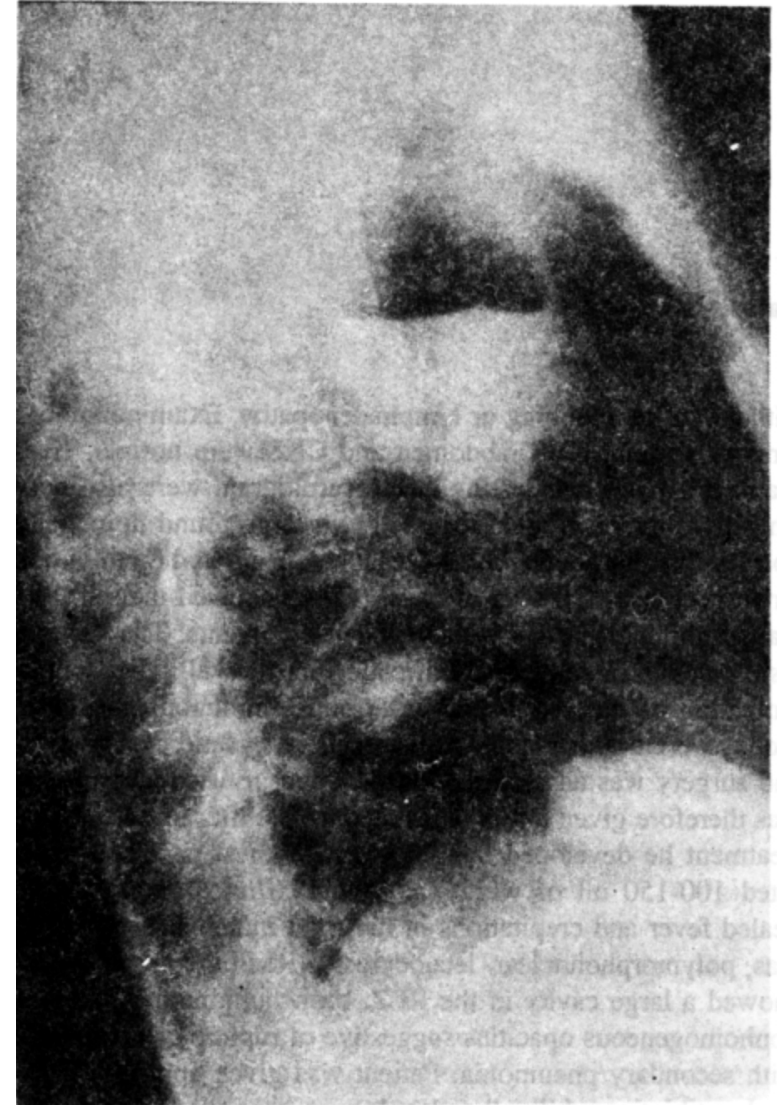

Fig. 3: 'Water lily' sign seen here is produced as a result of partial evacuation of fluid with kaminated membrane floating on the surface.

\section{Discussion}

Hydatid disease can involve any organ in the body. Lung is the second most common organ involved. Amongst 1802 patients in an Australian hydatid register, $25 \%$ had lesions in the lung [3].In an Indian series of 342 patients, lung involvement was seen in 150 cases [4]. Lower lobe involvement is more common than upper-lobe and right lobe more than the left. The most common mode of presentation is with complications, however our case had chest pain probably due to pressure effect. Eosinophilia was absent in this case, but it has been reported in $6.52 \%$ in various studies
[5]. Diagnosis rests on radiography, imaging and serology. CT-guided aspiration of hydatid cyst for diagnosis has been used successfully in some centers. Although surgery has been the standard treatment for hydatid cysts, it carries a mortality of 0.9 to $3.6 \%$ with recurrence upto $11.3 \%$ within 5 years [6]. Several newer nonsurgical options are now available including chemotherapy and percutaneous aspiration. In 1977 Mebendazole became the first drug to show activity against hydatid cysts. Albendazole is currently the drug of choice with reasonable cure rates [7]. Morris et al treated 20 patients with Albendazole and reported a cure in 5 , improvement in 10 and no response in 5 [8]. We treated our patient with Albendazole using a dose of $15 \mathrm{mg} /$ day. Both the cysts ruptured while on treatment, resulting in bronchopulmonary fistula and secondary pneumonia. Fortunately there was no anaphylactoid reaction. Rupture of the cyst as a complication of therapy has not been reported earlier. Patient is being followed up to detect dissemination of disease in the lung.

\section{REFERENCES}

1. Kulpati DDS. Pulmonary hydatid disease. In: Ahuja MMS. Progress in clinical medicine. 3rd series. N Delhi:Arnold Heinemann. 1979;441-58.

2. Upadhyay GH, Rai P, Shahi PK. Clinical study of hydatid disease in Jamnagar, J Ind Med Ass 1974;63:213.

3. Sadreih M, Dutz W, Navapoor MS. Review of 150 cases of hydatid cysts of the lung. Dis Chest 1967:52:662.

4. Radford AJ. Hydatid disease. In Weatherall DJ, Ledingham JGG, Warell LDA, editors. Oxford textbook of medicine 3rd ed. 1996;955-9.

5. McPhil JL, Arora TS. Intrathoracic hydatid disease. Dis Chest 1967:52:772.

6. Kumar A, Lal BK, Chattopadhyay TK. Hydatid disease of the liver-Nonsurgical options. J Assoc Phy Ind 1993;41:437-9.

7. Gil-Grande LA, Rodriguez-Caabeiro F, Prieto GJ etal. Randomised controlled trial of efficacy of albendazole in hydatid disease. Br Med J 1983;286:103-4.

8. Morris DL. Preoperative albendazole therapy for hydatid cysts. Br J Surg 1987;74:805-6. 